\title{
Important contribution of macroalgae to oceanic carbon sequestration
}

3 Alejandra Ortega ${ }^{1}$, Nathan R. Geraldi ${ }^{1}$, Intikhab Alam ${ }^{2}$, Allan A. Kamau ${ }^{2}$, Silvia G. Acinas ${ }^{3}$,

4 Ramiro Logares ${ }^{3}$, Josep M. Gasol ${ }^{3,4}$, Ramon Massana ${ }^{3}$, Dorte Krause-Jensen ${ }^{5}$ and Carlos M.

5 Duarte ${ }^{1,2^{*}}$

6

$7 \quad 1$ Red Sea Research Center (RSRC), King Abdullah University of Science and Technology

$8 \quad$ (KAUST), Thuwal, Saudi Arabia

92 Computational Bioscience Research Center (CBRC), King Abdullah University of

$10 \quad$ Science and Technology (KAUST), Thuwal, Saudi Arabia

113 Institut de Ciències del Mar, CSIC, Barcelona, Spain

124 Centre for Marine Ecosystem Research, Edith Cowan University, Joondalup, Australia

135 Department of Bioscience, and Arctic Research Centre, Aarhus University, Denmark

\section{Abstract}

16 The role of macroalgae in Blue Carbon assessments has been controversial, partially due to

17 uncertainties on the fate of exported macroalgae. Available evidence suggests that macroalgae is

18 exported to reach the open ocean and the deep-sea. Nevertheless, this evidence lack of systematic

19 assessment. Here, we provide robust evidence of macroalgal export beyond coastal habitats. We

20 used metagenomes and metabarcodes from the global expeditions Tara Oceans and Malaspina

212010 Circumnavigation. We discovered macroalgae worldwide at up to 5,000 $\mathrm{km}$ from coastal

22 areas. We found 24 orders, most of them belong to Rhodophyta. Diversity of macroalgae was

23 similar across oceanic regions, although the assemblage composition differed. The South 
24 Atlantic Ocean presented the highest macroalgal diversity; the Red Sea was the least diverse 25 region. Abundance of macroalgae sequences attenuated exponentially with depth at a rate of $2637.3 \% \mathrm{~km}^{-1}$, and only $24 \%$ of macroalgae available at the surface were expected to reach the 27 seafloor at $4,000 \mathrm{~m}$ depth. Our findings indicate that macroalgae is exported across the open and 28 the deep ocean, suggesting that macroalgae may be an important source of allochthonous carbon, 29 and their contribution should be considered in Blue Carbon assessments. 
31 Coastal habitats are highly productive ecosystems that contribute greatly to global carbon

32 sequestration ${ }^{1,2}$. Seagrass meadows, salt marshes and mangrove forests have complex root

33 systems that sequester large amounts of carbon in soft sediments within their habitat ${ }^{3-6}$.

34 Macroalgae have been neglected in Blue Carbon assessments ${ }^{7,8}$, because most of them lack root

35 systems, grow on rocky substrate, and do not accumulate carbon-rich sediments. However,

36 macroalgae form the most extensive and productive vegetated coastal habitat, exporting over

$3744 \%$ of their primary production ${ }^{1,7,9}$. Calculations suggest that $25 \%$ of exported macroalgal

38 carbon is sequestered in long-term reservoirs, such as coastal sediments and the deep sea ${ }^{1,7}$.

39 Based on first-order calculations ${ }^{7}$, it is hypotesized that macroalgae globally support an export

40 of $679 \mathrm{Tg} \mathrm{C}$ year $^{-1}$. Most of this carbon is remineralized or grazed in coastal environments, or

41 cast onshore, while $14 \mathrm{Tg} \mathrm{C}$ year $^{-1}$ is sequestered in coastal sediments and $152 \mathrm{Tg} \mathrm{C}_{\mathrm{gear}}{ }^{-1}$ could

42 be sequestered in the deep sea ${ }^{7}$. Although there is a lack of empirical data, these calculations are

43 supported by annecdotal evidence from sightings of long-distance macroalgae rafting ${ }^{10}$ and

44 presence in deep-sea sediments ${ }^{7}$. This evidence is dominated by observation of large biomass of

45 brown macroalgae (Phaeophyta), but observations of red (Rhodophyta) and green (Chlorophyta)

46 macroalgae are few ${ }^{10}$. This evidence imbalance could be related to lineage-specific features of

47 the macroalgae cell wall composition and differences in cell-degradation rates ${ }^{11}$. Furthermore,

48 most calculations of macroalgal primary production suggest that macroalgal carbon is exported

49 as dissolved and particulate organic carbon (DOC and POC $)^{12,13}$, which are not visually

50 detectable. An inclusive method, such as the identification of macroalgal environmental DNA

51 (eDNA), could provide evidence of macroalgal carbon export in the ocean, and may allow the

52 required systematic and consistent assessments. eDNA is the DNA left behind by organisms in 
53 the surrounding environment including degraded cell tissues, gametes, animal feces, etc. As

54 DNA comprises approximately $3 \%$ of cellular organic carbon ${ }^{14}$, the presence of macroalgal DNA

55 in waters beyond macroalgal habitats is both an indicator of the presence of the species and

56 evidence (not necessarily quantitative) of the export of macroalgal carbon.

57 Here, we examined the presence and relative abundance of Rhodophyta, Phaeophyta, and

58 Chlorophyta macroalgal eDNA sequences in the ocean. The sequences were derived from

59 hundreds of metagenomes generated by two global expeditions: Tara Oceans ${ }^{15}$ and Malaspina

602010 Circumnavigation ${ }^{16}$. These expeditions surveyed the global ocean from surface to $4,000 \mathrm{~m}$

61 depth, and sequenced the particulate material present in environmental water samples ${ }^{17,18}$ (see

62 Methods). Although the expeditions primarily assessed the microbial and planktonic diversity,

63 they also generated a global DNA resource that allows identification of multicellular eukaryotes.

64 We exploited the potential of this eukaryotic eDNA resource to explore the presence of

65 macroalgae in the global ocean. This holistic approach has not been attempted before, but is

66 semi-quantitative and consistent for evaluating the hypothesis that macroalgal material is broadly

67 exported across the global ocean.

68 We identified macroalgae using two global ocean datasets. The first one included 163

69 metabarcodes of amplicon $18 \mathrm{~S}$ rDNA from Tara Oceans ${ }^{19}$. The second one included 417

70 metagenomes pooled from the Tara Oceans ${ }^{20}$ and Malaspina ${ }^{21}$ expeditions (see Methods). We

71 used two different strategies for the second dataset: (a) a query targeting all genes (AG), and (b)

72 restricting the query to the top four single-copy protein-encoding genes (SCG) available in the

73 gene catalogue of both expeditions. Since macroalgae taxonomy is not well covered in barcoding

74 and genome reference libraries ${ }^{22}$, we used order instead of species as the taxonomical level for 75 macroalgae identification. 


\section{Tracing macroalgae in the oceanic particulate organic matter}

78 Combining the results of the three independent datasets, 24 macroalgae orders were identified

79 within the particulate organic matter (POM) of the water column. Both metagenomic approaches

80 (AG and SCG) delivered seventeen orders, of which ten were shared among the two approaches

81 (Table 1). Only six orders were detected in the amplicon 18S rDNA metabarcodes, all of them

82 found in the metagenomes. Rhodophyta was the most common macroalgal lineage (18 orders: 12

83 in AG, 13 in SCG, and 4 in the 18S dataset), followed by Phaeophyta (4 orders: 2 unique in each

84 metagenomic approach), and Chlorophyta (2 orders: 2 in AG, and 1 shared in both SCG and 18S

85 datasets; Table 1).

86 The relative abundance of macroalgal DNA varied between oceanic basins and datasets. The

87 Mediterranean Sea presented the highest abundance of sequences in both 18S and AG datasets,

88 while the South Atlantic Ocean was the most abundant in the SCG dataset. The basins with the

89 fewest sequences were the Red Sea in the 18S dataset, the Southern Ocean in AG and the

90 Mediterranean Sea in the SCG dataset. Similarly, the relative abundance of sequences per order

91 differed greatly. Cyanidiales (Rhodophyta) and Ectocarpales (Phaeophyta) jointly accounted for

$9257 \%$ of the macroalgal sequences in both metagenomic datasets, although they were absent from

93 the amplicon 18S dataset, whose most abundant order was Prasiolales (Chlorophyta) with 53\%

94 of all macroalgal sequences (Table 1).

95 Our pioneering attempt to trace macroalgal eDNA from POM in the global ocean is

96 challenging for two reasons. Firstly, the phylogenetic diversity of macroalgae is so great that the

97 three lineages are as distant from each other as are mushrooms from elephants ${ }^{8}$. Secondly,

98 macroalgal sequences are poorly represented in reference libraries. Metagenomic and 
99 metabarcoding identification is restricted to previously sequenced taxa that are available in

100 published databases. Sequencing efforts on macroalgae are rather limited, with only one full

101 genome sequenced ${ }^{23}$. Half of the 24 orders identified here are not included in the SILVA 18S

102 rDNA reference library (http://www.arb-silva.de, accessed on July 2018). Furthermore, SILVA

103 includes only 1,068 macroalgae species, compared with 12,471 species reported in the

104 AlgaeBase and the 27,500 described species ${ }^{22}$. SILVA underrepresents green and brown

105 macroalgae in comparison with red algae: Chlorophyta and Phaeophyceae have 46 and 84 entries

106 for macroalgae respectively, while Rhodophyta has 938 entries (searched in July 2018).

107 Analogously, macroalgae do not have any single-copy protein-encoding gene reported in the

108 EggNOG database (http://eggnogdb.embl.de, searched in February 2018), as most proteins are

109 reported for model organisms such as Oryza sativa, Arabidopsis thaliana or Saccharomyces

110 cerevisiae. Because of this scarcity in macroalgae reference sequences, there is an

111 underestimation of macroalgae (false-negatives) and a bias in the taxonomic representation of the

112 macroalgae contributing POM. There is a need for enhanced molecular resources for macroalgae,

113 especially for single markers. A single marker (i.e. 18S rDNA gene) enhances accurate

114 identification to species level, and could draw phylogenetic relationships among lineages. A

115 robust genomic reference will allow the detection of species in the POC and DOC pools,

116 enabling the use of eDNA-based approaches to assign relative contributions of species to the

117 carbon available in the ocean.

118 Macroalgae taxonomical identification in all datasets was performed by matching the

119 sequences against available DNA references. Macroalgae sequences were less abundant in the

120 18S metabarcoding dataset, with only $29 \%$ of orders available in the metagenomes. Thus, the 
121 metagenomes make it easier to find macroalgal DNA in the water column, given the poor and

122 highly unbalanced representation of macroalgae in the SILVA 18S library.

123 Macroalgal material is likely to be exported from their coastal habitats as whole thalli or

124 fragments, that either degrade progressively or are rapidly delivery to the deep-sea ${ }^{7}$. Although

125 marine eDNA decays within a few days ${ }^{24,25}$, the drifting macroalgal biomass ${ }^{7}$ is constantly

126 leaving traces of its DNA. eDNA recovered from metagenomes is the snapshot evidence of the

127 macroalgal biomass exported to the sampling location from the coastal habitat. However, it is

128 uncertain whether the relative abundance of sequences per order truly reflects the contribution of

129 each order within the macroalgal export flux. The focus on metagenomic single-copy protein-

130 encoding genes provides a parsimonious approach for assessing relative abundance of

131 macroalgae. A single-copy gene occurs once in the genome, accounts for a single cell, and

132 represents one individual in microbial communities ${ }^{26}$. In multicellular organisms, the relative

133 abundance of DNA sequences from SCG may be scaled to the relative number of cells (and

134 amount of biomass) available per taxon. Thus, the abundance pattern of macroalgal SCG from

135 different taxa may be expected to correlate with their contribution to carbon export.

136 Given these caveats for metagenomes, and considering that the $18 \mathrm{~S}$ metabarcodes were

137 limited to fewer samples, we chose the SCG dataset for further analyses of macroalgal order

138 diversity and macroalgal biomass export in the open and deep ocean. We believe that the SCG

139 approach is likely less biased and more informative than the other two approaches.

\section{Macroalgal diversity in the ocean}

142 Macroalgal taxonomic composition in the SCG dataset was similar across oceanic regions.

143 Cyanidiales and Ectocarpales were the most ubiquitous and abundant orders across all the basins. 
144 Cyanidiales represented $35 \%$ of macroalgal DNA sequences. This result was unexpected but

145 may be possibly related to the fact that Cyanidiales is the earliest Rhodophyta and other orders

146 could share enough nucleotides in the sequences that may be identified as Cyanidiales.

147 Nevertheless, we aligned these DNA sequences and the phylogeny separates Rhodophyta orders

148 (Supplementary Fig. 1). Furthermore, Cyanidiales is known for its metabolic capacities and their

149 ability to colonize extreme habitats ${ }^{27}$. Ectocarpales, the most diverse order of Phaeophyta (774

150 species in AlgaeBase ${ }^{28}$ ), accounted for $22 \%$ of the DNA sequences (Table 1, Fig. 1a). The

151 Atlantic and North Pacific Oceans were the most diverse regions, while the Red Sea (the smallest

152 basin sampled) was the least diverse (Supplementary Table 1, Fig. 1a). The South Atlantic Ocean

153 displayed the highest percentage of macroalgal DNA (17\% of the total across all basins), while

154 the lowest was found in the Mediterranean Sea and the Indian Ocean (8\% each). A high

155 abundance of macroalgae was observed poleward of $40^{\circ}$ in both the Northern (21\%) and

156 Southern (28\%) Hemisphere (Fig. 1a), possibly reflecting high local production of macroalgae at

157 these latitudes. The Arctic supports abundant macroalgae populations along its extensive rocky

158 coastline $^{29}$, and the Norwegian Atlantic current may collect significant inputs of boreal

159 macroalgal detritus. Similarly, there is evidence of export of Antarctic kelps, brown macroalgae

160 of the order Laminariales, that could potentially be transported over long distances by the

161 Antarctic Circumpolar Current ${ }^{30}$. In addition, macroalgal material may be preserved longer at

162 low water temperatures than at the warmer found at tropical latitudes ${ }^{31}$. Since many species

163 contain air-vesicles that confer buoyancy, polar latitudes could be a dead end for macroalgal

164 material, as has been shown to be the case for plastic accumulation driven by surface

165 circulation $^{32}$. 
One-way PERMANOVA revealed significant differences in the SCG macroalgal DNA assemblage across oceans $(p=0.0001 ; d f=7,347 ; \mathrm{F}=4.7)$. The Red Sea, Indian Ocean and

168 South Pacific Ocean were significantly different to the other oceanic regions (pairwise $p<0.005$;

169 Supplementary Table 2). Nevertheless, cluster analysis and non-metric multi-dimensional scaling 170 (nMDS) ordination indicated similarities in the assemblages (Fig. 1b-c). Most regions were

171 above $75 \%$ similarity, with the exceptions of the Red Sea (60\%) and the Mediterranean Sea 172 (65\% similarity). Differences between overall PERMANOVA and ordination indicate a

173 dispersion effect, as confirmed with significant difference in variance between groups

174 (PERMDISP $p<0.0001 ; d f=7,347 ; \mathrm{F}=5.7)$.

\section{Export of macroalgae throughout the water column}

177 The Malaspina expedition sampled eDNA from surface to 4,000 m, while for Tara the

178 maximum sampling depth was $1,000 \mathrm{~m}$. Consequently, analyses of oceanic macroalgal

179 abundance include only the Malaspina dataset. Macroalgae order diversity varied between depth

$180 \quad($ PERMANOVA $p=0.001 ; d f=2,352 ; \mathrm{F}=43.6$; pairwise $p<0.05 ;$ PERMDISP $p<0.0001 ; d f=$

$1812,352 ; \mathrm{F}=31.7)$. The epipelagic zone $(0-200 \mathrm{~m})$ was the most diverse, while the least diverse

182 was the mesopelagic zone (200-1,000 m, Supplementary Table 3). The relative abundance of

183 macroalgal DNA (and likely macroalgal carbon) attenuates exponentially with depth at a rate of

$18437.3 \% \mathrm{~km}^{-1}$ (Fig. 2a). This value is much lower than the attenuation rate of sinking POC flux in

185 the Northeast Pacific Ocean down to 5,000 $\mathrm{m}\left(86 \% \mathrm{~km}^{-1}\right.$, based on data from Martin et al. $\left.{ }^{33}\right)$.

186 However, a lower value for the global-ocean attenuation rate is fairly expected due to the

187 refractory nature of macroalgae carbon which degrade slower in comparison to degradation of 
188 planktonic $\mathrm{POC}^{34}$. These results provide the first large-scale quantitative evidence of macroalgal 189 transport to the to the deep sea, validating previous assumptions of vertical export ${ }^{7}$.

190 Most macroalgae grow in coastal areas. Exceptions are the drifting Sargasso Sea, and 191 macroalgae living on shallow oceanic seamounts ${ }^{35,36}$. Oceanic and biological processes (e.g. 192 storms, senescence) promote coastal detachment, dispersion and export of macroalgae to the 193 open ocean ${ }^{7,37}$. Contrary to the exponential attenuation by depth, there was no difference in 194 macroalgal abundance from the shoreline to distances up to $4,860 \mathrm{~km}$ (PERMANOVA $p=$ $1950.194 ; d f=6,223 ; \mathrm{F}=1.2$; Fig. 2b). This observation corroborates the estimated widespread 196 export of macroalgal material to the open ocean, hitherto based on anecdotal evidence.

197 Rhodophyta can tolerate long periods of darkness and remain photosynthetic at great 198 depths $^{38,39}$. Furthermore, these macroalgae cover the largest geographical extent and support the 199 largest global production ${ }^{38}$. Thus, Rhodophyta would be estimated to export more material than 200 Phaeophyta and Chlorophyta. Our results confirm these assertions: several red algae were 201 present at high depths, and $63 \%$ of the DNA sequences belonged to Rhodophyta, compared with $20226 \%$ for Phaeophyta and 11\% for Chlorophyta (Table 1, Fig. 3). Likewise, Rhodophyta were 203 taxonomically more abundant than Phaeophyta and Chlorophyta (13>3>1 order, respectively).

204 This richness is expected: the AlgaeBase shows a greater diversity of red algae (6,245 classes, 30 205 orders,) than brown (1,792 classes, 13 orders) or green algae (546 classes, 15 orders $)^{8,22}$. The low 206 oceanic richness of Chlorophyta in the exported POM could be related to morphological and 207 biochemical features. Rhodophyta and Phaeophyta contain taxon-specific polysaccharides that 208 provide structural complexity and recalcitrancy ${ }^{40}$. Fucoidans (in brown algae) and carrageenans 209 (in red algae) bind to the cell wall and protect from desiccation and microbial cell-invasion, 210 hence delaying degradation ${ }^{11,41-43}$. These features are absent in green algae ${ }^{41}$. Such recalcitrance- 
211 promoting compounds may enhance long-distance transport of Rhodophyta and Phaeophyta, as

212 supported by their prevalence in the oceanic particulate organic matter pool.

\section{Implication for Blue Carbon assessment}

215 Our findings demonstrate the ubiquitous presence of macroalgal DNA in the ocean up to

$2164,000 \mathrm{~m}$ depth and 4,860 $\mathrm{km}$ away from the nearest coastline. The attenuation rate of macroalgae

$217\left(37.3 \% \mathrm{~km}^{-1}\right)$ implies that $69 \%$ of the macroalgal DNA available at the surface will sink below

$2181,000 \mathrm{~m}$. Oceanic models demonstrate that the carbon reaching 1,500 $\mathrm{m}$ depth is sequestered

219 close to permanent time-scales ${ }^{44}$ in terms of climate change mitigation. Hence, the macroalgal

220 material (and organic carbon) that reaches 1,000 $\mathrm{m}$ (the boundary between mesopelagic and

221 bathypelagic layers ${ }^{45}$ ) will be sequestered and prevented from exchanging with the atmosphere

222 over extended timescales ${ }^{7,44}$. Moreover, $24 \%$ of macroalgal DNA sequences sinking from the

223 surface will be expected to reach the seafloor (assuming mean oceanic depth of 3,800 m). Our

224 results also revealed an increase in the relative abundance of Laminariales (i.e. kelp) DNA in

225 POM between 3,000 and 4,000 m (Fig. 3a), consistent with the reported bedload bulk-transport

226 of kelp to the deep sea ${ }^{7}$. This transport is influenced by episodic storm-driven events ${ }^{7,46}$ that

227 detach and rapidly sink macroalgae; this rapid sink is due to the presence of heavy rocky

228 substrate retained by macroalgae in their holdfast. Submarine canyons support intense bedload

229 fluxes of kelp, thereby delivering macroalgae (along with their DNA sequences and carbon)

230 directly into the deep sea ${ }^{7,47-49}$. Through this mechanism, a larger biomass of Laminariales is

231 delivered to the deep sea, while the remaining orders progressively degrade into smaller and

232 smaller fragments, thus attenuating exponentially with increasing depth. 
233 While the global ocean metagenomes analyzed here were produced to explore the oceanic

234 microbiome, the data also allow detection of eukaryotic organisms such as macroalgae.

235 Metagenomes are an unexplored tool for fingerprinting the contributions of different organisms

236 to POM in the ocean. This research is a first step supporting the role of macroalgae as an

237 important allochthonous source of Blue Carbon sequestered in the deep sea. Our eDNA approach

238 provides robust evidence of the widespread oceanic presence of macroalgae, and our data

239 support the hypothesis of macroalgae export to the open and deep ocean hitherto based on

240 estimations ${ }^{1,7}$. As DNA is also cellular organic carbon ${ }^{14}$, we infer that the presence of the taxa

241 evidences the export of macroalgal carbon. Nevertheless, calculations of the macroalgal carbon

242 exported to the ocean require experimentally-determined ratios between carbon and DNA

243 content per taxon, which are currently unknown. Although the ultimate fate of oceanic

244 macroalgal material remains uncertain, it is clear that a significant fraction reaches oceanic sinks

245 while another is grazed and degraded by bacteria, thus subsidizing oceanic food webs. 


\section{References}

2471 Duarte, C. M. \& Cebrián, J. The fate of marine autotrophic production. Limnol.

248 Oceanogr. 41, 1758-1766(1996).

2492 Duarte, C. M. \& Krause-Jensen, D. Export from seagrass meadows contributes to marine 250 carbon sequestration. Front. Mar. Sci. 4, 13 (2017).

2513 McLeod, E. et al. A blueprint for blue carbon: toward an improved understanding of the 252 role of vegetated coastal habitats in sequestering $\mathrm{CO}_{2}$. Front. Ecol. Environ. 9, 552-560

253 (2011).

2544 Fourqurean, J. W. et al. Seagrass ecosystems as a globally significant carbon stock. Nat. 255 Geosci. 5, 505-509 (2012).

2565 Duarte, C. M., Kennedy, H., Marbà, N. \& Hendriks, I. Assessing the capacity of seagrass 257 meadows for carbon burial: current limitations and future strategies. Ocean Coast.

$258 \quad$ Manage. 83, 32-38 (2013).

2596 Donato, D. C. et al. Mangroves among the most carbon-rich forests in the tropics. Nat. 260 Geosci. 4, 293-297 (2011).

2617 Krause-Jensen, D. \& Duarte, C. M. Substantial role of macroalgae in marine carbon 262 sequestration. Nat. Geosci. 9, 737-742 (2016).

2638 Krause-Jensen, D. et al. Sequestration of macroalgal carbon: the elephant in the Blue 264 Carbon room. Biol. Lett. 14, 20180236 (2018).

2659 Duarte, C. M. Reviews and syntheses: Hidden forests, the role of vegetated coastal 266 habitats in the ocean carbon budget. Biogeosciences 14, 301-310 (2017).

26710 Garden, C. J. \& Smith, A. M. Voyages of seaweeds: The role of macroalgae in sediment 268 transport. Sediment. Geol. 318, 1-9 (2015). 
26911 Kloareg, B. \& Quatrano, R. S. Structure of the cell walls of marine algae and

270 ecophysiological functions of the matrix polysaccharides. Oceanogr. Mar. Biol. 26, 259-

$271 \quad 315(1988)$.

27212 Barrón, C., Apostolaki, E. T. \& Duarte, C. M. Dissolved organic carbon fluxes by

273 seagrass meadows and macroalgal beds. Front. Mar. Sci. 1, 42 (2014).

$27413 \quad$ Krumhansl, K. A. \& Scheibling, R. E. Production and fate of kelp detritus. Mar. Ecol.

275 Prog. Ser. 467, 281-302 (2012).

27614 Landenmark, H. K. E., Forgan, D. H. \& Cockell, C. S. An estimate of the total DNA in

277 the biosphere. PLoS Biol. 13, e1002168 (2015).

27815 Karsenti, E. et al. A holistic approach to marine eco-systems biology. PLoS Biol. 9,

$279 \quad$ e1001177 (2011).

28016 Duarte, C. M. Seafaring in the 21st century: the Malaspina 2010 Circumnavigation

281 Expedition. Limnol. Oceanogr. 24, 11-14 (2015).

28217 Salazar, G. et al. Global diversity and biogeography of deep-sea pelagic prokaryotes.

283 ISME J. 10, 596-608 (2016).

28418 Hingamp, P. et al. Exploring nucleo-cytoplasmic large DNA viruses in Tara Oceans

285 microbial metagenomes. ISME J. 7, 1678-1695 (2013).

28619 De Vargas, C. et al. Eukaryotic plankton diversity in the sunlit ocean. Science 348, $287 \quad 1261605(2015)$.

28820 Pesant, S. et al. Open science resources for the discovery and analysis of Tara Oceans 289 data. Sci. Data 2, 150023 (2015). 
29021 Sánchez, P. et al. in Supplement to: Ortega et al. Macroalgae are Important Contributors

291 to Oceanic Carbon Export and Sequestration, https://doi.org/10.5281/zenodo.2596829

$292 \quad$ (2019).

29322 Guiry, M. D. How many species of algae are there? J. Phycol. 48, 1057-1063 (2012).

29423 Cock, J. M. et al. The Ectocarpus genome and the independent evolution of

295 multicellularity in brown algae. Nature 465, 617 (2010).

29624 Collins, R. A. et al. Persistence of environmental DNA in marine systems. Commun.

297 Biol. 1, $185(2018)$.

29825 Thomsen, P. F., Kielgast, J., Iversen, L.L., Møller, P.R., Rasmussen, M., Willerslev, E.

299 Detection of a diverse marine fish fauna using environmental DNA from seawater

$300 \quad$ samples. PLoS One 7, e41732 (2012).

30126 Roux, S., Enault, F., le Bronner, G. \& Debroas, D. Comparison of 16S rRNA and

302 protein-coding genes as molecular markers for assessing microbial diversity (Bacteria

303 and Archaea) in ecosystems. FEMS Microbiol. Ecol. 78, 617-628 (2011).

30427 Seckbach, J. \& Chapman, D. J. Red algae in the genomic age (Springer, 2010).

30528 Guiry, M. D. AlgaeBase. World-wide electronic publication, http://www.algaebase.org

$306 \quad$ (2013).

30729 Krause-Jensen, D. \& Duarte, C. M. Expansion of vegetated coastal ecosystems in the 308 future Arctic. Front. Mar. Sci. 1, 77 (2014).

$30930 \quad$ Kaehler, S., Pakhomov, E. A., Kalin, R. M. \& Davis, S. Trophic importance of kelp310 derived suspended particulate matter in a through-flow sub-Antarctic system. Mar. Ecol.

$311 \quad$ Prog. Ser. 316, 17-22 (2006). 
31231 Kelaher, B. P., Coleman, M. A. \& Bishop, M. J. Ocean warming, but not acidification, 313 accelerates seagrass decomposition under near-future climate scenarios. Mar. Ecol. Prog. 314 Ser. 605, 103-110 (2018).

31532 Cózar, A. et al. The Arctic Ocean as a dead end for floating plastics in the North Atlantic 316 branch of the Thermohaline Circulation. Sci. Adv. 3 (2017).

31733 Martin, J. H., Knauer, G. A., Karl, D. M. \& Broenkow, W. VERTEX: carbon cycling in 318 the northeast Pacific. Deep Sea Res. (II Top. Stud. Oceanogr.) 34, 267-285 (1987).

31934 Enríquez, S., Duarte, C. M. \& Sand-Jensen, K. A. J. Patterns in decomposition rates 320 among photosynthetic organisms: the importance of detritus C:N:P content. Oecol. 94, $321 \quad 457-471(1993)$.

32235 Carpenter, E. J. \& Cox, J. L. Production of pelagic Sargassum and a blue green epiphyte 323 in the western Sargasso Sea. Limnol. Oceanogr. 19, 429-436 (1974).

32436 Woodborne, M. W., Rogers, J. \& Jarman, N. The geological significance of kelp-rafted 325 rock along the west coast of South Africa. Geo-Mar. Lett 9, 109-118 (1989).

32637 Garden, C. J., Currie, K., Fraser, C. I. \& Waters, J. M. Rafting dispersal constrained by 327 an oceanographic boundary. Mar. Ecol. Prog. Ser. 501, 297-302 (2014).

32838 Gattuso, J. P. et al. Light availability in the coastal ocean: impact on the distribution of 329 benthic photosynthetic organisms and contribution to primary production. Biogeosciences $330 \quad 3,895-959(2006)$.

33139 Littler, M. M., Littler, D. S., Blair, S. M. \& Norris, J. N. Deepest known plant life 332 discovered on an uncharted seamount. Science 227, 57-59 (1985).

33340 Trevathan-Tackett, S. M. et al. Comparison of marine macrophytes for their contributions 334 to blue carbon sequestration. Ecology 96, 3043-3057 (2015). 
33541 Percival, E. The polysaccharides of green, red and brown seaweeds: their basic structure, 336 biosynthesis and function. Br. Phycol. 14, 103-117 (1979).

33742 Shukla, P. S., Borza, T., Critchley, A. T. \& Prithiviraj, B. Carrageenans from red 338 seaweeds as promoters of growth and elicitors of defense response in plants. Front. Mar. 339 Sci. 3, 81 (2016).

34043 Berteau, O. \& Mulloy, B. Sulfated fucans, fresh perspectives: structures, functions, and 341 biological properties of sulfated fucans and an overview of enzymes active toward this 342 class of polysaccharide. Glycobiology 13, 29R-40R (2003).

34344 Herzog, H., Caldeira, K. \& Reilly, J. An issue of permanence: assessing the effectiveness 344 of temporary carbon storage. Clim. Change 59, 293-310 (2003).

34545 Robinson, C. et al. Mesopelagic zone ecology and biogeochemistry-a synthesis. Deep 346 Sea Res. (II Top. Stud. Oceanogr.) 57, 1504-1518 (2010).

34746 Dierssen, H. M., Zimmerman, R. C., Drake, L. A. \& Burdige, D. J. Potential export of 348 unattached benthic macroalgae to the deep sea through wind driven Langmuir $349 \quad$ circulation. Geophys. Res. Lett. 36 (2009).

35047 De Leo, F. C., Smith, C. R., Rowden, A. A., Bowden, D. A. \& Clark, M. R. Submarine 351 canyons: hotspots of benthic biomass and productivity in the deep sea. Proc. R. Soc.

352 Lond., Ser. B: Biol. Sci., rspb20100462 (2010).

35348 Canals, M. et al. Flushing submarine canyons. Nature 444, 354 (2006).

35449 Harrold, C. \& Lisin, S. Radio-tracking rafts of giant kelp: local production and regional 355 transport. J. Exp. Mar. Biol. Ecol. 130, 237-251 (1989). 
357 Correspondence to C. M. Duarte, carlos.duarte@kaust.edu.sa.

359 Acknowledgements

360 We thank Tara Oceans Consortium for data availability. This research was supported by the 361 Malaspina 2010 Expedition, funded by the Spanish Ministry of Economy and Competitiveness

362 through the Consolider-Ingenio program to CMD (Reference CSD2008-00077); CARMA,

363 funded by the Independent Research Fund Denmark to DKJ (Reference 8021-00222B); and King

364 Abdullah University of Science and Technology's project BAS/1/1071-01-01 to CMD. We thank

365 all the scientists and crew for their support during sample collection on the Malaspina 2010

366 cruise, and especially E. Borrull, C. Díez-Vives, E. Lara, D. Vaqué, G. Salazar, and F. Cornejo-

367 Castillo for DNA sampling.

369 Author Contributions

370 CMD and DKJ conceived the research; JMG, SA, RL, RM, IA and AAK produced and

371 curated the data; $\mathrm{AO}, \mathrm{CMD}, \mathrm{NRG}$ and IA conducted the data analysis; $\mathrm{AO}$ and CMD wrote the 372 manuscript. All coauthors contributed to improve the manuscript and approved the submission.

\section{Competing interests}

375 The authors declare no competing interests. 


\section{Figure captions}

377 Fig. 1: Assemblage of macroalgae in the ocean. a, Global distribution of macroalgae. Pie size 378 represents DNA abundance per region: highest abundance in South Pacific Ocean (17\%), lowest

379 abundance in Mediterranean Sea and Indian Ocean (8\%). Bar-graph shows latitudinal

380 distribution of total macroalgal DNA, with $50 \%$ abundance beyond $40^{\circ} \mathrm{N}$ and $40^{\circ} \mathrm{S}$ (RPM, reads

381 per million \pm SE). b, Bray-Curtis similarity cluster and c, nMDS comparing macroalgal

382 assemblage across oceanic regions.

384 Fig. 2: Export of macroalgae to the deep and open ocean. a, Vertical attenuation profile of 385 macroalgal DNA in the Malaspina single-copy protein-encoding genes (SCG) dataset. Dashed

386 line shows fitting curve based on power law equation of $y$. The calculated attenuation coefficient

387 is indicated by $b$ (see Methods). b, Horizontal export of macroalgal DNA from shoreline 388 (continent or island) to open ocean (sampling point), based on Tara and Malaspina epipelagic 389 metagenomes (0-200 m depth; RPM, reads per million $\pm \mathrm{SE})$.

391 Fig. 3: Oceanic export of macroalgal DNA relative abundance per order. a, Depth

392 attenuation of macroalgae from surface to bathypelagic zone (4,000 m), using Malaspina

393 metagenomes. Most orders attenuated with depth, with the exception of Prasiolales and

394 Laminariales. b, Macroalgal DNA export from shoreline to open ocean, based on Tara and

395 Malaspina epipelagic metagenomes (0-200 $\mathrm{m}$ depth). Presence of macroalgae is ubiquitous in the 396 open ocean. RPM, reads per million. 
398 Table 1 Relative abundance of macroalgal DNA. IO Indian Ocean $(n=87,11 ; 87$ SCG and

399 AG metagenomes, 11 metabarcodes for 18S), MS Mediterranean Sea $(n=19,18)$; NAO, SAO

400 North $(n=44,2)$ and South Atlantic Ocean $(n=101,21)$; NPO, SPO North $(n=51,0)$ and

401 South Pacific Ocean $(n=88,18)$, RS Red Sea $(n=13,2)$, and SO Southern Ocean $(n=14,6)$.

402 Order Abundance indicates percentage of each order among total macroalgal DNA sequences per

403 dataset. Order Prevalence indicates percentage of metagenomes/metabarcodes $(n)$ where the

404 order was present. Cyanidiales represented $35 \%$ of the SCG dataset (reads per million \pm SE) and

405 was present in $72 \%$ of the metagenomes. Prasiolales dominated the $18 \mathrm{~S}$ dataset: $53 \%$ of the total

406 sequences (metagenomic Illumina tags $\pm \mathrm{SE}$ ) and found in $66 \%$ of the metabarcodes 


\section{Methods}

408 Macroalgae taxa are included in two of the eight major lineages of the Eukaryota domain ${ }^{50}$, 409 where they belong to 4 kingdoms, 15 phyla and 54 classes $^{22}$. Marine macroalgae are found in

410 three phyla (Rhodophyta, Phaeophyta, Chlorophyta), which also contain microalgae.

411 Chlorophyta (green algae) are closer to vascular plants than to Rhodophyta (red algae) or to

412 Phaeophyta (brown algae), which are closer to molds than to other macroalgae ${ }^{22,50,51}$. Macroalgae

413 groups have broad differences in cell wall composition ${ }^{11}$. Even the same order of algae can have

414 strong divergences among genera ${ }^{52}$. Thus, macroalgae classification is very diverse, and the term

415 macroalgae describes functional groups that are not necessarily related phylogenetically to each

416 other even at phylum level. Identification of macroalgal DNA sequences is a challenging

417 process: there is no universal gene marker ${ }^{53}$, and barcoding attempts are limited to certain

418 groups $^{53,54} .18 \mathrm{~S}$ rDNA barcoding resources are poorly represented: only $3.8 \%$ of macroalgae are

419 reported in the SILVA database (1,068 of 27,500 described species ${ }^{22}$, http://www.arb-silva.de,

420 searched on July 2018). Nevertheless, the available (and limited) molecular resources based on a

421 single gene marker are an important tool for accurately identifying macroalgae, and also for

422 drawing phylogenetic conclusions about these taxa.

423 However, less strict approaches can also be used to identify marine macroalgae groups when

424 resolution at species level is not required. Since DNA represents 3\% of cellular organic carbon ${ }^{14}$, 425 here we infer the carbon export of marine macroalgae phyla with the presence of macroalgal

426 DNA in the water column. We investigated occurrence of macroalgae in the open and deep

427 ocean, using global metagenomes and metabarcodes generated by the Tara Oceans ${ }^{15}$ and

428 Malaspina 2010 Circumnavigation ${ }^{16}$ expeditions. 
431 Tara sampling covered epipelagic and mesopelagic zones (5-1,000 m) across eight oceanic

432 regions, with a total of 210 sampling stations: North Atlantic Ocean, South Atlantic Ocean,

433 North Pacific Ocean, South Pacific Ocean, Indian Ocean, Southern Ocean, Mediterranean Sea,

434 and Red Sea. Each location was sampled at different depths (surface water layer 3-7 m, deep

435 chlorophyll maximum layer 30-70 m, mesopelagic zone 400-1.000 m), using CTD and Niskin

436 bottle Rosette sampling system ${ }^{17,18,20}$. We used 243 metagenomic samples that targeted the gene

437 pool of viral to metazoan plankton, using multiple filters to isolate distinct size-fractions of the

438 suspended particle pool (0.1-0.22 $\mu \mathrm{m} 20$ samples, $<0.22 \mu \mathrm{m} 45$ samples, $0.22-0.45 \mu \mathrm{m} 18$

439 samples, 0.45-0.8 $\mu \mathrm{m} 21$ samples, 0.22-1.6 $\mu \mathrm{m} 36$ samples, and 0.22-3 $\mu \mathrm{m} 103$ samples $)^{20}$. We

440 used 163 metabarcodes from the $18 \mathrm{~S}$ rDNA aimed at piconano- to meso-plankton communities

441 (size-fractions: $<0.8 \mu \mathrm{m} 28$ samples, 0.22-3 $\mu \mathrm{m} 1$ sample, 0.8-5 $\mu \mathrm{m} 60$ samples, 0.8-20 $\mu \mathrm{m} 6$

442 samples, 5-20 $\mu \mathrm{m} 23$ samples, 20-180 $\mu \mathrm{m} 31$ samples, and 180-2000 $\mu \mathrm{m} 14$ samples) ${ }^{19}$. Water

443 samples were kept at $-20^{\circ} \mathrm{C}$ on board and at $-80{ }^{\circ} \mathrm{C}$ in the laboratory until DNA extraction, then

444 DNA was kept at $-20{ }^{\circ} \mathrm{C}$ until sequencing ${ }^{55}$. Detailed sampling and methods are available for 445 metagenomes in Pesant et al. ${ }^{20}$, and for $18 \mathrm{~S}$ rDNA amplicons in De Vargas et al. ${ }^{19}$.

446 The Malaspina expedition sampled open-ocean waters from surface to 4,018 m depth, with

447 emphasis on the bathypelagic zone $(1,000-4,000 \mathrm{~m})^{16}$. Water samples were collected using CTD

448 and Niskin bottle Rosette sampling system, at 70 sampling stations across the oceans and

449 grouped into the eight oceanic regions used by Tara (see above). Filters containing the particle

450 pools sampled in the water were flash frozen in liquid nitrogen and stored at $-80{ }^{\circ} \mathrm{C}$ until DNA

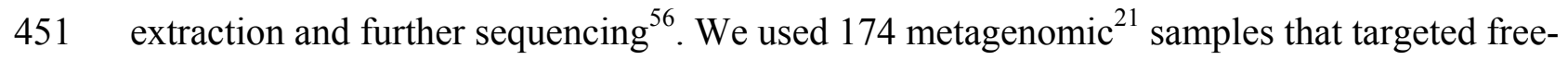


452 living bacteria to picoeukaryotes and nanoeukaryotes (size-fractions: $0.2-0.8 \mu \mathrm{m} 29$ samples, $0.2-$ $4533 \mu \mathrm{m} 100$ samples, 0.8-20 $\mu \mathrm{m} 31$ samples, and 3-20 $\mu \mathrm{m} 14$ samples).

454 Together, these expeditions used massive DNA sequencing and generated hundreds of 455 metagenomes to assess oceanic microbial and planktonic diversity ${ }^{18}$. Tara also generated a global 456 Eukaryotic DNA resource based on $18 \mathrm{~S}-\mathrm{V} 9^{11} \mathrm{rDNA}$ amplicons. This data collection did not aim

457 to survey macro-organisms. Nevertheless, we exploited their potential to reveal macroalgal 458 genes. Data came from 153 Tara and 65 Malaspina sampling stations across the oceans, from the 459 surface to 4,000 m (Supplementary Fig. 2).

460 We identified DNA sequences of Rhodophyta, Phaeophyta, and Chlorophyta using two 461 datasets: (1) amplicon 18S rDNA-based metabarcodes from Tara Oceans, and (2) metagenomes 462 that contain the whole gene pool from both Tara Oceans and Malaspina. These macroalgal DNA 463 sequences belonged to 20,212 unique genes available in the reference gene catalogs of both 464 expeditions (Supplementary Table 4). We believe this holistic approach has not been tried 465 before.

467 Amplicon 18S data extraction

468 For the first dataset, denoted 18S, single amplicon reads were extracted from 163 Tara $^{57}$ 469 metabarcodes of the 18S rDNA V9 hyper-variable loop. Metabarcodes were blasted against 470 SILVA 18S rDNA database (SILVA Release 132, http://www.arb-silva.de). Macroalgae 471 taxonomy is not well described ${ }^{22}$, and sequences from the $18 \mathrm{~S}$ rDNA are scarce in the SILVA 472 database (only $3.8 \%$ representation, searched on July 2018); thus, to avoid false-negative results, 473 we chose order rather than species as the taxonomical level. The search was taxonomically 474 restricted to taxa Viridiplantae, Stramenopiles and Rhodophyta. The resulting taxonomical list 
475 was filtered manually by choosing all macroalgae orders whose sequences presented an identity

476 percentage cut-off $>90 \%$. A cut-off of $90 \%$ is above the accepted threshold for order level (84-

$\left.47790 \%{ }^{58-62}\right)$.

478 Malaspina 18S rDNA metabarcodes, though available ${ }^{63}$, were excluded for several reasons:

479 Malaspina sequenced the 18S rDNA V4 region, and the sampling and sequencing effort was

480 much lower than in Tara. The contribution of Malaspina to the amplicon 18S dataset was limited

481 to only 7 samples presenting any macroalgae sequence, in contrast to 78 samples from Tara.

\section{Metagenomic data extraction}

484 For the second dataset, denoted as metagenomes, we used 243 Tara $^{20}$ and 174 Malaspina $^{21}$

485 metagenomes to find macroalgal DNA sequences in the open ocean. We used two different

486 strategies: (a) targeting all genes (AG), and (b) restricting the query to the top four single-copy

487 protein-encoding genes (SCG) available in the gene catalogs of both expeditions. Each strategy

488 generated its own new dataset. Metagenomic data were analyzed using the Dragon

489 Metagenomics analysis platform (DMAP, http://www.cbrc.kaust.edu.sa/dmap). DMAP re-

490 annotated Tara Oceans and Malaspina metagenomic gene catalogs, keeping the original reads

491 that are based on gene abundance for each sample (units are in reads per million, RPM).

492 DMAP uses UniProt Knowledgebase as a reference database to compare genes from Tara and

493 Malaspina's gene catalogs. To assign taxonomy and generic functional role, DMAP uses high-

494 throughput BLASTp that are examined to traverse lowest common ancestor along the best hits.

495 Specific functional role is assigned using BLASTp against KEGG Orthologs from KEGG

496 database. This taxonomic and functional role information is indexed for all genes, and made

497 available for lookups and sample comparisons in the Compare module of DMAP. In this module, 
we restricted both metagenomic strategies (AG and SCG) to taxa Viridiplantae (DMAP filter

499 taxID: 33090), Stramenopiles (taxID: 33634) and Rhodophyta (taxID: 2763); the search was

500 restricted to coverage and identity percentage cut-offs greater than or equal to $90 \%$. A higher cut-

501 off recovers fewer sequences (false-negatives). Identification of macroalgae in the metagenome

502 dataset is based on protein similarity. Proteins are very conserved at higher taxonomic levels,

503 thus a threshold of $90 \%$ is above the mean percentage identity for proteins $(70 \%)^{64}$.

504 The SCG strategy (b) included additional steps. Initially, we wanted to restrict the search to

505 single-copy protein-encoding genes specifically from Chlorophyta, Rhodophyta or Phaeophyta,

506 but there were none available in the reference database (EggNOG ${ }^{65}$, searched on February 2018).

507 Thus, we searched for the top four single-copy protein-encoding genes present in Viridiplantae,

508 Stramenopiles and Rhodophyta within the expeditions' gene catalogs; we used the $K E G G$

509 Ortholog module of DMAP. Back to the Compare module, we individually restricted the SCG

510 search to each one of these top four protein-encoding genes: NADH:ubiquinone reductase (EC:

511 1.6.5.3), N-acetyl-gamma-glutamyl-phosphate reductase (EC: 1.2.1.38), DNA-directed RNA

512 polymerase (EC: 2.7.7.6), and non-specific serine/threonine protein kinase (EC: 2.7.11.1).

513 Order was used as the level for taxonomical assignment, because most macroalgae species

514 have an incomplete genome reference library and undescribed taxonomy ${ }^{22}$. The initial search

515 using species as taxonomical level returned false-negative BLAST hits. For instance, when the

516 search was restricted to a few species of the order Ectocarpales, DMAP did not return any

517 sequence because the dataset is incomplete; sequences were returned when we searched directly

518 for the order. The databases include unknown or uncultured sequences that are assigned to higher

519 taxonomic ranks, e.g. order. The search generated a taxonomical list, where we manually filtered

520 all macroalgae orders that returned sequences. 


\section{Data analyses}

523 A list of macroalgae orders and the relative abundance of the sequences was obtained from

524 each dataset (18S metabarcodes, metagenomes AG and metagenomes SCG). Relative abundance

525 is reported in the metagenomes as reads per million (RPM), and as Illumina tags (mi Tags) for the

526 18S dataset. Each sample included information on depth, size-fraction and location. To account

527 for unequal sampling effort within each oceanic region, the relative abundance of sequences was

528 standardized by dividing the total number of sequences of each order in each oceanic region by

529 the number of samples within each oceanic region.

530 We performed Bray-Curtis Similarity clustering and non-metric multidimensional scaling

531 (nMDS) ordination to elucidate differences in macroalgal assemblage among oceanic regions.

532 One-way permutational multivariate analysis of variance (PERMANOVA) and analysis of

533 homogeneity of multivariate dispersion (PERMDISP) based on Bray-Curtis similarities were

534 performed to test for differences in macroalgal assemblage composition across oceanic basins;

535 data were log-transformed prior these analyses. These analyses were done in $\mathrm{R}$ using the Vegan ${ }^{66}$

536 package. To evaluate how taxonomic richness and relative abundance of the sequences is

537 distributed among oceanic regions, we calculated the indices of Pielou equitability (J),

538 Dominance (D) and Shannon (H); these indices assess evenness, dominance and diversity at

539 order level. To compare observed order richness with estimated richness, we calculated the index

540 CHAO 2. Indices were calculated in $\mathrm{PAST}^{67}$. Order diversity was also evaluated through the

541 water column from surface to 4,000 $\mathrm{m}$ using only the Malaspina dataset; the Tara dataset is

542 limited to $1,000 \mathrm{~m}$ depth. 
The global distribution of macroalgal DNA sequences was analyzed by assessing export and

544 relative abundance with depth from the surface to the deep ocean (vertically), and with distance

545 from the sampling point to the closest shoreline (horizontally). Vertical export was analyzed by

546 comparing Malaspina macroalgae sequences through the water column zones: epipelagic $(0-200$

$547 \mathrm{~m})$, mesopelagic (200-1,000 m) and bathypelagic zone (1,000-4,000 m). Attenuation of

548 macroalgae sequences with depth was modeled by fitting relative abundance of each zone to a

549 normalized power function, following the coefficient ${ }^{33}$ for particulate organic carbon flux:

$550 \quad y=a x^{-b}$,

551 where $y$ is macroalgae relative abundance, $a$ is the intercept, $x$ is the depth, and $b$ is the

552 macroalgae attenuation coefficient (sequences in $\mathrm{RPM} \mathrm{m}^{-1}$ ). Relative abundance of macroalgal

553 DNA by depth was standardized, dividing the total number of sequences per depth category by

554 the number of samples within each depth category (0-200 m; $500 \mathrm{~m} ; 1,000 \mathrm{~m} ; 2,000 \mathrm{~m} ; 3,000 \mathrm{~m}$;

555 and 4,000 $\mathrm{m}$; maximum depth recorded was 4,018 $\mathrm{m}$ ).

556 Horizontal export was analyzed by comparing relative abundance of macroalgae sequences

557 with distance from the sampling point to the closest shoreline (continent or island) using one-

558 way permutational multivariate analysis of variance (PERMANOVA). These data consisted of

559 Tara and Malaspina metagenomes that belong to the epipelagic zone $(0-200 \mathrm{~m})$. The relative

560 abundance of macroalgal DNA was standardized, dividing the total number of sequences per

561 distance category by the number of samples within each distance category $(0-200 \mathrm{~km} ; 500 \mathrm{~km}$;

$5621,000 \mathrm{~km} ; 2,000 \mathrm{~km} ; 3,000 \mathrm{~km} ; 4,000 \mathrm{~km}$; and 5,000 km; maximum distance recorded was 4,860

$563 \mathrm{~km})$.

565 Data availability 
566 The data that support the findings on this study are available in: Pesant et al. ${ }^{20}$ (Tara Oceans 567 metagenomes, doi: 10.1038/sdata.2015.23), De Vargas et al. ${ }^{57}$ (Tara Oceans 18S rDNA V9 568 metabarcodes, doi: 10.1126/science.1261605); and Zenodo (Malaspina metagenomes, doi: $56910.5281 /$ zenodo.2596829) ${ }^{21}$. 
$57150 \quad$ Baldauf, S. L. The deep roots of eukaryotes. Science 300, 1703-1706 (2003).

57251 Zuccarello, G. C., Price, N., Verbruggen, H. \& Leliaert, F. Analysis of a plastid

573 multigene data set and the phylogenetic position of the marine macroalga Caulerpa

574 filiformis (Chlorophyta). J. Phycol. 45, 1206-1212 (2009).

57552 Nakada, T., Misawa, K. \& Nozaki, H. Molecular systematics of Volvocales (Chlorophyceae, Chlorophyta) based on exhaustive 18S rRNA phylogenetic analyses. Mol. Phylogenet. Evol. 48, 281-291 (2008).

57853 Saunders, G. W. \& Kucera, H. An evaluation of rbcL, tufA, UPA, LSU and ITS as DNA 579 barcode markers for the marine green macroalgae. Cryptogamie Algol. 31, 487 (2010).

58054 Saunders, G. W. Applying DNA barcoding to red macroalgae: a preliminary appraisal 581 holds promise for future applications. Philos. Trans. R. Soc. Lond. B Biol. Sci. 360, 18791888 (2005).

58355 Clerissi, C. et al. Unveiling of the diversity of Prasinoviruses (Phycodnaviridae) in marine samples by using high-throughput sequencing analyses of PCR-amplified DNA polymerase and major capsid protein genes. Appl. Environ. Microbiol. 80, 3150-3160 (2014).

$58756 \quad$ Pernice, M. C. et al. Large variability of bathypelagic microbial eukaryotic communities across the world's oceans. ISME J. 10, 945 (2015).

58957 De Vargas, C., Tara Oceans Expedition, P. \& Tara Oceans Consortium, C. in Supplement to: De Vargas, C. et. al. (2015): First Tara Oceans V9 rDNA metabarcoding dataset, https://doi.org/10.1594/PANGAEA.843017 (2015). 
59258 Lanzén, A. et al. CREST-classification resources for environmental sequence tags. PLoS

$593 \quad$ One 7, e49334 (2012).

59459 Cole, J. R., Konstantinidis, K., Farris, R. J. \& Tiedje, J. M. in Environmental molecular

595 biology (eds Wen-Tso Liu \& Janet K. Jansson) Ch. Microbial diversity and phylogeny:

596 extending from rRNAs to genomes, 1-20 (Horizon Scientific Press, 2010).

59760 Giongo, A., Davis-Richardson, A. G., Crabb, D. B. \& Triplett, E. W. TaxCollector:

598 modifying current $16 \mathrm{~S}$ rRNA databases for the rapid classification at six taxonomic

599 levels. Diversity 2, 1015-1025 (2010).

60061 Hong, S.-H., Bunge, J., Jeon, S.-O. \& Epstein, S. S. Predicting microbial species

601 richness. Proc. Natl. Acad. Sci. U. S. A. 103, 117-122 (2006).

60262 Schloss, P. D. \& Handelsman, J. Status of the microbial census. Microbiol. Mol. Biol.

$603 \quad \operatorname{Rev} .68,686-691(2004)$.

60463 Giner, C. R. et al. Marked changes in diversity and relative activity of picoeukaryotes

605 with depth in the global ocean. Preprint at https://www.biorxiv.org/node/177912.abstract

$606 \quad 552604(2019)$.

60764 Krause, L. et al. Taxonomic composition and gene content of a methane-producing

608 microbial community isolated from a biogas reactor. J. Biotechnol. 136, 91-101 (2008).

60965 Huerta-Cepas, J. et al. eggNOG 4.5: a hierarchical orthology framework with improved

610 functional annotations for eukaryotic, prokaryotic and viral sequences. Nucleic Acids Res.

$611 \quad 44$, D286-D293 (2015).

61266 Oksanen, J. et al. Vegan: Community ecology package. $R$ Doc 10, 631-637 (2007).

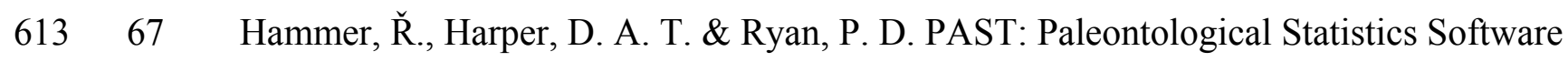

614 Package for Education and Data Analysis Palaeontol. Electron. 4, 9 (2001). 


\begin{tabular}{|c|c|c|c|c|c|c|c|c|c|c|c|c|}
\hline Dataset & Lineage & Order & IO & MS & NAO & NPO & RS & SAO & so & SPO & $\begin{array}{c}\text { \% Order } \\
\text { Abundance }\end{array}$ & $\begin{array}{c}\text { \% Order } \\
\text { Prevalence }\end{array}$ \\
\hline SCG & Chlorophyta & Prasiolales & $1.3( \pm 0.6)$ & $0.9( \pm 0.4)$ & $2.2( \pm 0.5)$ & $0.7( \pm 0.4)$ & $0.3( \pm 0.3)$ & $1.6( \pm 0.3)$ & $2.5( \pm 1.4)$ & $1.2( \pm 0.2)$ & 11.46 & 40.05 \\
\hline SCG & Phaeophyta & Ectocarpales & $1.1( \pm 0.3)$ & $4.1( \pm 1.4)$ & $2.1( \pm 0.5)$ & $3.7( \pm 1.2)$ & $0.9( \pm 0.3)$ & $2.1( \pm 0.3)$ & $4.3( \pm 1.5)$ & $2.1( \pm 0.4)$ & 21.87 & 49.40 \\
\hline SCG & Phaeophyta & Fragilariales & $0.2( \pm 0.1)$ & $0.4( \pm 0.1)$ & $0.9( \pm 0.3)$ & $0.1( \pm 0.0)$ & $0.4( \pm 0.2)$ & $0.6( \pm 0.2)$ & - & $0.3( \pm 0.2)$ & 3.11 & 17.75 \\
\hline SCG & Phaeophyta & Laminariales & $0.2( \pm 0.1)$ & - & - & $0.2( \pm 0.2)$ & - & $0.2( \pm 0.1)$ & - & - & 0.77 & 4.56 \\
\hline SCG & Rhodophyta & Bangiales & - & - & - & - & - & - & $0.1( \pm 0.1)$ & - & 0.14 & 1.44 \\
\hline SCG & Rhodophyta & Batrachospermales & - & - & - & - & - & $0.4( \pm 0.3)$ & $1.0( \pm 0.9)$ & - & 1.47 & 2.88 \\
\hline SCG & Rhodophyta & Bonnemaisoniales & - & - & - & $0.1( \pm 0.1)$ & - & - & - & - & 0.12 & 0.72 \\
\hline SCG & Rhodophyta & Ceramiales & - & - & - & - & - & - & - & - & 0.05 & 0.96 \\
\hline SCG & Rhodophyta & Corallinales & $0.1( \pm 0.0)$ & $0.1( \pm 0.1)$ & $0.3( \pm 0.2)$ & $0.1( \pm 0.0)$ & - & $1.3( \pm 0.5)$ & - & $0.1( \pm 0.0)$ & 2.14 & 15.83 \\
\hline SCG & Rhodophyta & Cyanidiales & $3.0( \pm 0.7)$ & $1.8( \pm 0.7)$ & $3.6( \pm 0.8)$ & $2.5( \pm 0.5)$ & $7.6( \pm 4.9)$ & $4.8( \pm 1.1)$ & $2.6( \pm 0.7)$ & $7.1( \pm 1.2)$ & 35.31 & 72.42 \\
\hline SCG & Rhodophyta & Gelidiales & $0.1( \pm 0.0)$ & $0.2( \pm 0.2)$ & - & $0.1( \pm 0.0)$ & - & $0.5( \pm 0.2)$ & $0.1( \pm 0.1)$ & $0.1( \pm 0.0)$ & 1.14 & 6.24 \\
\hline SCG & Rhodophyta & Gigartinales & $1.2( \pm 0.2)$ & $0.1( \pm 0.1)$ & $0.8( \pm 0.2)$ & $1.1( \pm 0.3)$ & $0.6( \pm 0.3)$ & $0.7( \pm 0.2)$ & $0.9( \pm 0.6)$ & $1.1( \pm 0.2)$ & 6.90 & 46.52 \\
\hline SCG & Rhodophyta & Halymeniales & $0.1( \pm 0.1)$ & - & $0.2( \pm 0.1)$ & $0.4( \pm 0.2)$ & - & $0.3( \pm 0.1)$ & $0.2( \pm 0.2)$ & $0.2( \pm 0.1)$ & 1.58 & 9.35 \\
\hline SCG & Rhodophyta & Nemaliales & $0.5( \pm 0.2)$ & $0.1( \pm 0.0)$ & $2.3( \pm 0.8)$ & $1.1( \pm 0.4)$ & $0.1( \pm 0.1)$ & $2.3( \pm 0.6)$ & $2.4( \pm 2.1)$ & $3.6( \pm 0.7)$ & 13.22 & 32.61 \\
\hline SCG & Rhodophyta & Palmariales & - & - & - & - & - & - & $0.1( \pm 0.1)$ & - & 0.18 & 1.44 \\
\hline SCG & Rhodophyta & Plocamiales & - & - & - & - & - & - & - & - & 0.01 & 0.24 \\
\hline SCG & Rhodophyta & Rhodymeniales & - & - & - & - & - & $0.3( \pm 0.1)$ & - & $0.2( \pm 0.0)$ & 0.54 & 13.19 \\
\hline $\mathrm{AG}$ & Chlorophyta & Prasiolales & $0.0( \pm 0.1)$ & - & $0.0( \pm 0.1)$ & - & - & $0.1( \pm 0.3)$ & $0.2( \pm 0.2)$ & - & 1.21 & 7.91 \\
\hline AG & Chlorophyta & Ulvales & - & - & - & - & - & $0.1( \pm 0.1)$ & - & - & 0.28 & 1.44 \\
\hline AG & Phaeophyta & Ectocarpales & $0.4( \pm 1.5)$ & $0.1( \pm 0.4)$ & $0.7( \pm 2.5)$ & $0.6( \pm 1.8)$ & $0.7( \pm 2.0)$ & $0.9( \pm 2.0)$ & $0.3( \pm 0.5)$ & $0.7( \pm 3.1)$ & 25.10 & 30.22 \\
\hline $\mathrm{AG}$ & Phaeophyta & Fucales & - & - & - & - & - & - & - & - & 0.06 & 0.48 \\
\hline AG & Phaeophyta & Laminariales & - & - & - & - & - & - & - & - & 0.07 & 6.71 \\
\hline AG & Rhodophyta & Balliales & $0.4( \pm 0.6)$ & - & - & $0.1( \pm 0.1)$ & - & $0.6( \pm 0.8)$ & $0.2( \pm 0.3)$ & $0.4( \pm 0.6)$ & 4.33 & 6.71 \\
\hline AG & Rhodophyta & Bangiales & $0.8( \pm 1.5)$ & $0.3( \pm 0.5)$ & $0.1( \pm 0.5)$ & $0.3( \pm 0.8)$ & $0.1( \pm 0.1)$ & $0.3( \pm 1.0)$ & $0.9( \pm 1.4)$ & $0.2( \pm 0.7)$ & 11.87 & 33.09 \\
\hline AG & Rhodophyta & Ceramiales & - & - & - & - & - & - & $0.1( \pm 0.1)$ & - & 0.15 & 0.48 \\
\hline AG & Rhodophyta & Corallinales & - & - & - & - & - & - & - & - & 0.04 & 0.48 \\
\hline AG & Rhodophyta & Cyanidiales & $0.2( \pm 0.6)$ & $8.3( \pm 9.0)$ & $0.4( \pm 1.6)$ & $0.4( \pm 1.4)$ & $0.4( \pm 0.7)$ & $0.5( \pm 1.5)$ & $0.6( \pm 1.8)$ & $0.2( \pm 1.3)$ & 32.41 & 44.12 \\
\hline AG & Rhodophyta & Gigartinales & $0.1( \pm 0.2)$ & - & $0.1( \pm 0.1)$ & $0.2( \pm 0.2)$ & - & $0.1( \pm 0.2)$ & $0.1( \pm 0.1)$ & $0.1( \pm 0.1)$ & 1.72 & 5.28 \\
\hline AG & Rhodophyta & Gracilariales & $0.1( \pm 0.1)$ & - & - & $0.3( \pm 0.3)$ & - & $0.1( \pm 0.2)$ & - & - & 1.05 & 1.92 \\
\hline $\mathrm{AG}$ & Rhodophyta & Hapalidiales & - & - & - & - & - & - & - & - & 0.08 & 0.48 \\
\hline AG & Rhodophyta & Nemaliales & $0.1( \pm 0.2)$ & $0.1( \pm 0.2)$ & $0.3( \pm 0.9)$ & $0.1( \pm 0.3)$ & $0.6( \pm 1.3)$ & $0.5( \pm 1.2)$ & - & $0.1( \pm 0.3)$ & 7.94 & 24.22 \\
\hline AG & Rhodophyta & Palmariales & - & - & - & $0.2( \pm 0.2)$ & $2.4( \pm 4.6)$ & - & - & - & 8.93 & 3.84 \\
\hline AG & Rhodophyta & Porphyridiales & - & - & - & - & - & - & - & - & 0.04 & 0.24 \\
\hline AG & Rhodophyta & Stylonematales & $0.0( \pm 0.1)$ & $0.2( \pm 0.3)$ & $0.2( \pm 0.5)$ & $0.1( \pm 0.2)$ & $0.1( \pm 0.2)$ & $0.3( \pm 1.0)$ & - & $0.1( \pm 0.4)$ & 4.71 & 19.42 \\
\hline $18 \mathrm{~S}$ & Chlorophyta & Prasiolales & $9.7( \pm 2.8)$ & $1.0( \pm 0.6)$ & $0.8( \pm 0.5)$ & - & $1.5( \pm 0.5)$ & $13.5( \pm 7.2)$ & $10.7( \pm 3.5)$ & $4.2( \pm 1.1)$ & 53.20 & 66.23 \\
\hline $18 \mathrm{~S}$ & Rhodophyta & Ceramiales & - & $16.8( \pm 14.6)$ & - & - & - & - & - & - & 21.63 & 12.99 \\
\hline $18 \mathrm{~S}$ & Rhodophyta & Gigartinales & - & $0.2( \pm 0.2)$ & - & - & - & - & - & - & 0.29 & 2.60 \\
\hline $18 \mathrm{~S}$ & Rhodophyta & Porphyridiales & $0.4( \pm 0.3)$ & $8.4( \pm 8.0)$ & $1.8( \pm 3.5)$ & - & - & $4.3( \pm 3.4)$ & $0.5( \pm 0.3)$ & $0.4( \pm 0.1)$ & 20.16 & 35.06 \\
\hline $18 \mathrm{~S}$ & Rhodophyta & Rhodymeniales & - & $3.7( \pm 3.5)$ & - & - & - & - & - & - & 4.73 & 3.90 \\
\hline
\end{tabular}

\section{Relative abundance of macroalgal DNA.}



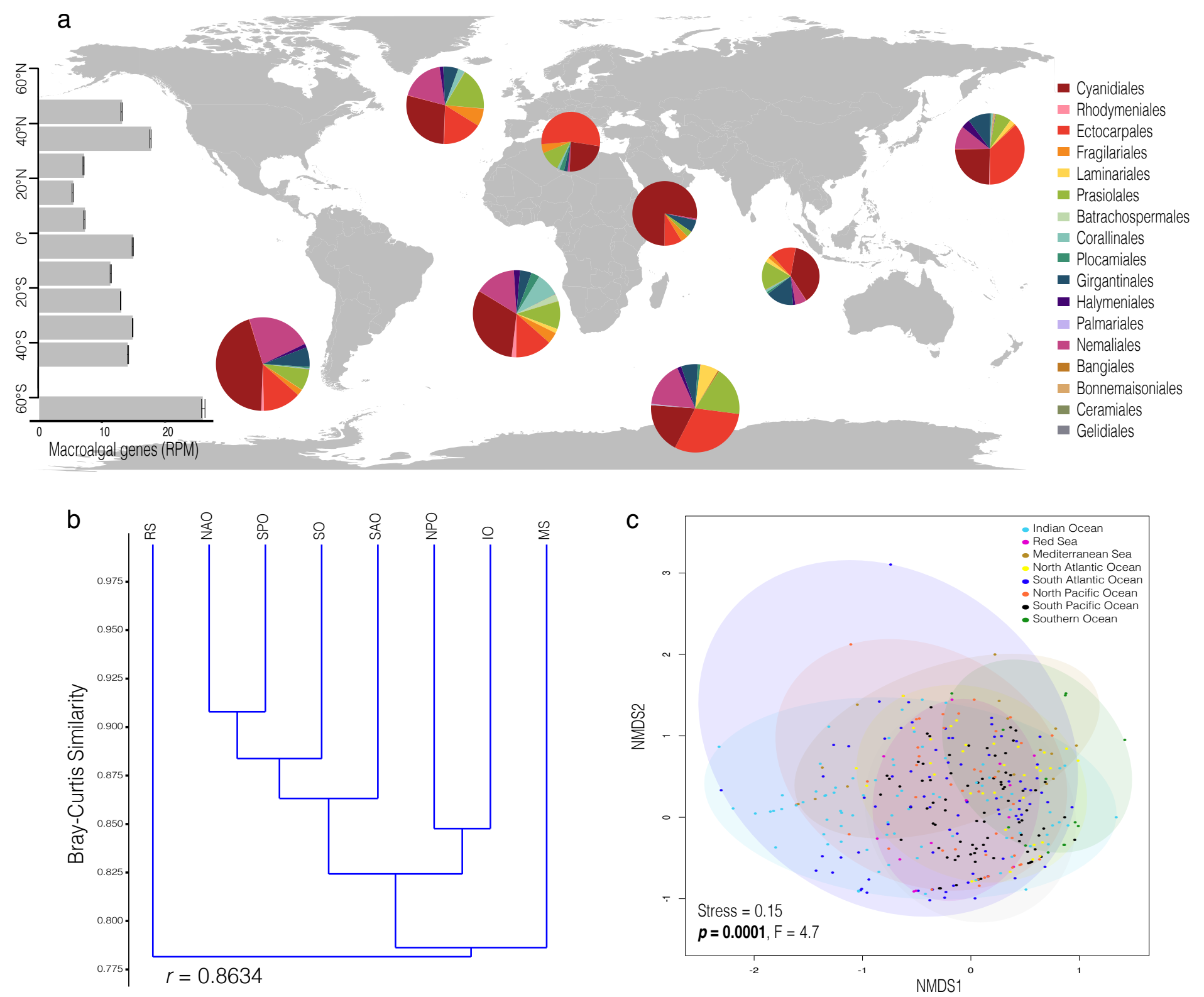

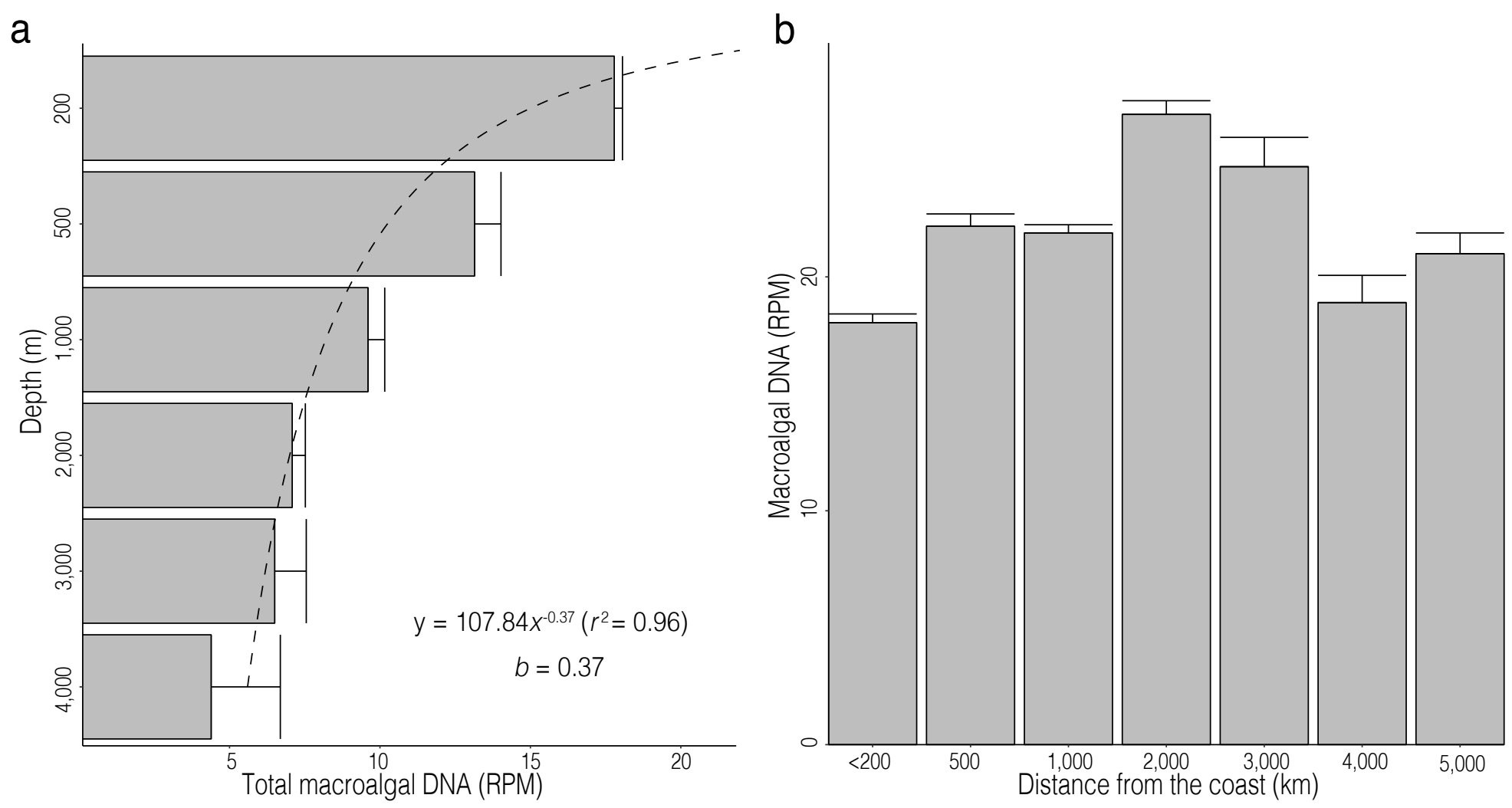


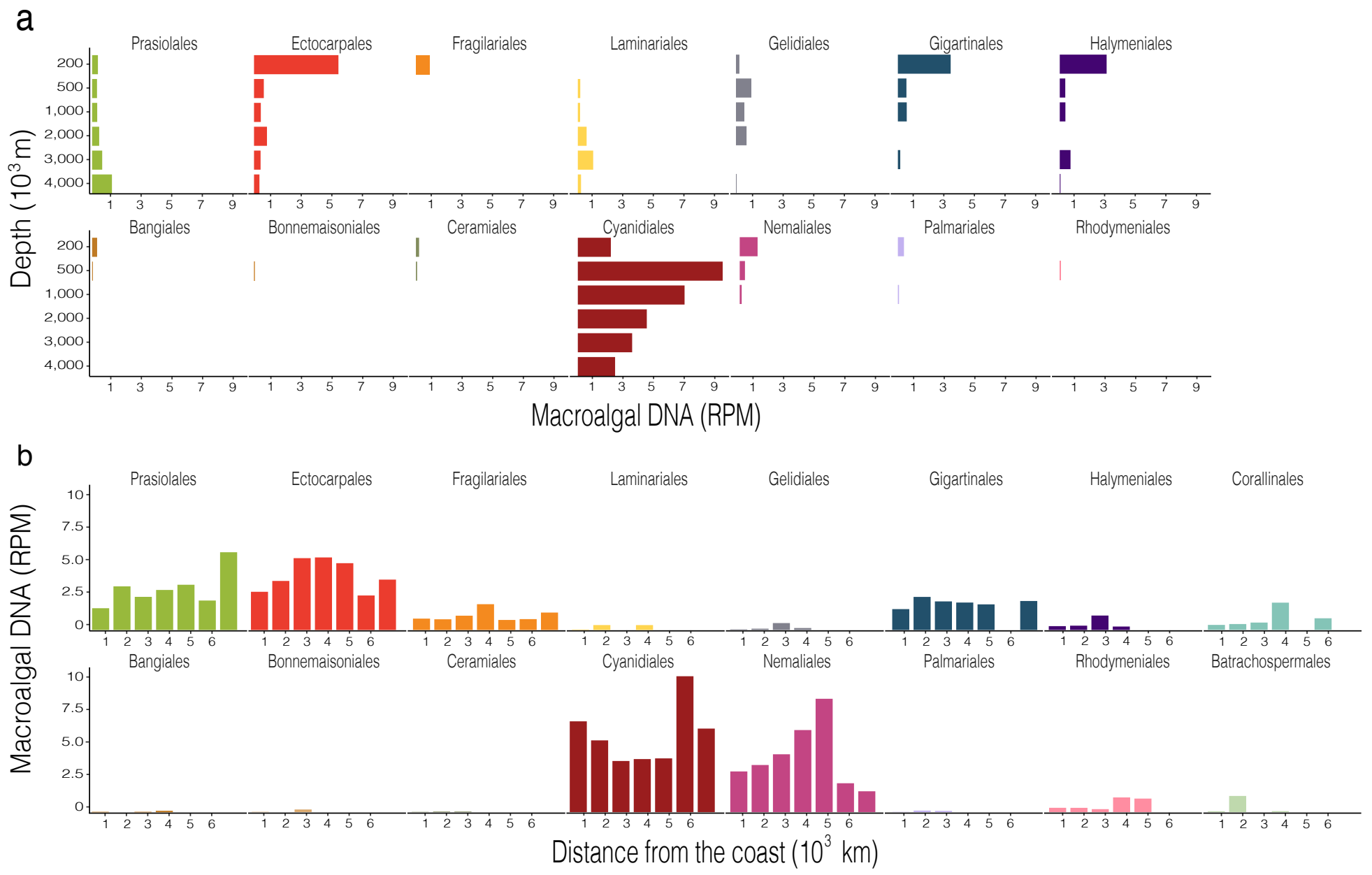

